\title{
PERBEDAAN PENGGUNAAN DRAIN DAN TANPA PENGGUNAAN DRAIN INTRA ABDOMEN TERHADAP LAMA PERAWATAN PASCAOPERASI LAPAROTOMI APENDISITIS PERFORASI
}

\section{THE DIFFERENCES OF USE OF DRAIN AND WITHOUT USE OF INTRA ABDOMEN DRAIN TO THE POSSIBLE PERSONAL CARE PERFORMANCE LAPAROTOMY APPLICATIONS}

\author{
Rahmadi Indra, Ida Bagus B.S.A, UntungAlfianto \\ Sub Bagian Bedah Digestif Fakultas Kedokteran Universitas Sebelas Maret \\ RSUD Dr Moewardi Surakarta \\ Korespondensi: dr. Rahmadi Indra, Sp. B. Email: Indrariqueza@yahoo.co.id
}

\begin{abstract}
ABSTRAK
Apendisitis menjadi salah satu kasus bedah abdomen yang paling sering terjadi di dunia. Apendisitis perforasi berhubungan dengan tingkat mortalitas yang tinggi. Peradangan akut pada apendiks perforasi memerlukan tindakan pembedahan segera untuk mencegah terjadinya komplikasi berbahaya. Tindakan pascabedah sangat diperlukan untuk mencegah komplikasi lanjutan. Pemasangan drain diharapkan mampu menurunkan risiko komplikasi abses intra-abdominal, meskipun demikian, drain intraabdomen setelah operasi apendisitis dalam kasus apendisitis perforasi masih kontroversi. Ada beberapa ahli bedah yang memilih untuk tidak memasang drain pasca bedah. Penelitian ini untuk mengetahui ada perbedaan penggunaan drain dan tanpa penggunaan drain intra abdomen terhadap lama perawatan pascaoperasi laparotomi apendisitis perforasi. Subjek penelitian ini adalah pasien apendisitis perforasi yang pasca-apendiktomi, dengan total sampel 20. Teknik sampling menggunakan random sampling. Jenis penelitian ini desain eksperimen semu (quasi experiment) dengan metode Posstest-Only Control Design. Dalam rancangan ini sampel dibagi menjadi dua kelompok yaitu, kelompok I dilakukan pemasangan drain intra abdomen dan kelompok II tidak dilakukan pemasangan drain kemudian dilakukan follow up untuk menilai lamanya perawatan pascaoperasi pada apendisitis perforasi. Mayoritas pasien pascaoperasi apendisitis perforasi berumur antara 40-60 tahun (45\%). Penyembuhan luka dan terjadinya komplikasi pasien pascaoperasi apendisitis perforasi baik yang dipasang drain maupun yang tidak dipasang drain semuanya mengalami proses penyembuhan luka dengan baik (100\%) dan tidak ada yang mengalami komplikasi (100\%). Lama perawatan pasien tanpa dipasang drain tercepat perawatan 4 hari dan paling lama 6 hari, sedangkan yang dipasang drain cenderung lebih lama, yaitu tercepat 5 hari dan terlama 8 hari. Ada perbedaan yang signifikan antara lama perawatan pasien pasca operasi apendisitis perforasi dengan yang dipasang drain dengan yang tidak dipasang drain dengan nilai $\mathrm{p}=0,001$. Secara statistik terdapat hubungan yang sangat signifikan antara lama perawatan pasien pascaoperasi apendisitis perforasi dengan yang dipasang drain dengan yang tidak dipasang drain.
\end{abstract}

Kata Kunci: Drain Apendisitis Perforasi, Lama Perawatan

\section{ABSTRACT}

Appendicitis is one of the most common cases of abdominal surgery in the world. Perforation appendicitis is associated with a high mortality rate. Acute inflammation of the perforation appendix requires immediate surgical treatment to prevent dangerous complications. Post surgical action is necessary to prevent further complications. Drainage is expected to reduce the risk of complications of intra-abdominal abscess, however, intra-abdominal drain after appendicitis surgery in cases of perforated appendicitis is still controversial. There are several surgeons who choose not to post a post surgical drain.Research purposes. To determine the difference between drain use and without the use of intra-abdominal drain on the length of postoperative care laparotomy appendicitis perforation. The subjects of this study were perforated appendicitis patients post-appendectomy, with a total sample of 20. Sampling technique using random sampling. This type of research is quasi experimental design with Posstest-Only Control Design method. In this design the sample was divided into two groups namely, group I done intra-abdominal drain installation and group II was not done drain installation and then performed follow up 
to assess the length of post-operative treatment on appendicitis perforation. The majority of post-operative patients perforated appendicitis are between 40-60 years old (45\%). Wound healing and the occurrence of post-operative complications of post-operative appendicitis perforated both drain and non-drained are all well-treated (100\%) and no complications (100\%). Duration of patient care without fastest drain treatment 4 days and maximum 6 days, while the drain tends to be longer, the fastest 5 days and the longest 8 days. There was a significant difference between the length of post-operative care of perforated appendicitis appendants with those drained with non-plunged drains with $p=0.001$. Statistically there is a very significant correlation between the length of post-operative care of perforated appendicitis apparatus with the placement of drain with the drain not installed.

Keywords: Drain Perforation Appendicitis, Length of Treatment

\section{PENDAHULUAN}

Apendisitis merupakan salah satu kasus bedah abdomen yang paling sering terjadi di dunia. Sebanyak $40 \%$ bedah emergensi di negara barat dilakukan atas indikasi apendisitis akut (Lee et al., 2010; Shrestha et al., 2012). Di Indonesia penderita apendisitis sekitar $27 \%$ dari jumlah pasien jumlah penduduk atau sekitar 179.000 orang. Insidens apendisitis menempati urutan tertinggi di antara kasus kegawatan abdomen lainnya (Depkes, 2011).

Apendisitis yang tidak tertangani segera akan meningkatkan risiko terjadinya perforasi dan pembentukan masa peri apendikular (Tzanakis, 2005; Vasser, 2012; Riwanto et al., 2010; Brunner \& Suddarth, 2014). Perforasi dengan cairan inflamasi dan bakteri masuk ke dalam rongga abdomen, lalu memberikan respons inflamasi permukaan peritoneum atau terjadi peritonitis. (Tzanakis, 2005; Brunner \& Suddarth, 2014).

Perforasi apendisitis berhubungan dengan tingkat mortalitas yang tinggi. Pasien yang mengalami apendisitis akut angka kematiannya hanya $1,5 \%$, tetapi ketika telah mengalami perforasi angka ini meningkat mencapai 20\%-35\% (Riwanto et al., 2010; Vasser, 2012). Pemasangan drain diharapkan mampu menurunkan risiko komplikasi abses intra-abdominal (Lund dan Murphy 1994;Fishman et al. 2000; St Peter et al 2008).

Drain intra abdomen banyak digunakan oleh ahli bedah di praktek klinis saat ini (Curran dan Muenchow 1993; Lund dan Murphy 1994; Fishman et al. 2000). Namun demikian, drain intra abdomen setelah operasi apendisitis dalam kasus apendisitis perforasi masih kontroversi (Akoyun, 2012). Ada beberapa ahli bedah yang memilih untuk tidak memasang drain pasca bedah. Banyak ahli bedah secara selektif menggunakan drain intra abdomen (Dandapat dan
Panda 1992; Yamini et all. 1998 ;Schwartz et all. 2014). Hasil penelitian yang pernah dilakukan sebelumnya tindakan pascaoperasi apendisitis perforasi yang dipasang drain mempunyai risiko lebih rendah terjadinya komplikasi dibandingkan dengan yang tidak dipasang drain, sehingga proses penyembuhan luka pasien yang dipasang drain lebih cepat dibandingkan dengan yang tidak dipasang (Memon, et al, 2002). Akan tetapi hasil penelitian yang dilakukan oleh Song (2015), mengatakan sebaliknya bahwa pemasangan drain dapat memperlama pasien dirawat di rumah sakit dan meningkatkan risiko mengalami abses dan infeksi.

Apendisitis perforasi adalah pecahnya apendiks yang sudah gangren yang menyebabkan pus masuk ke dalam rongga perut sehingga terjadi peritonitis umum. Pada dinding apendiks tampak daerah perforasi dikelilingi oleh jaringan nekrotik (Burkitt et al., 2007).

Pada kasus usus buntu yang sudah pecah/ mengalami perforasi sayatan luka operasi biasanya agak cukup lebar (bisa di samping/kanan bawah perut atau di bagian tengah perut-tegak lurus) dan umumnya disertai pemasangan drain (selang) di perut kanan bawah. Drain/selang ini fungsinya adalah untuk mengeluarkan/mengalirkan sisa bekuan darah/nanah yang berasal dari rongga perut (Jeo, 2009)

\section{METODE}

Penelitian ini menggunakan desain eksperimen semu (quasi experiment) dengan metode posttest-only control design. Dalam rancangan ini sampel dibagi menjadi dua kelompok yaitu, kelompok I dilakukan pemasangan drain intra abdomen dan kelompok II tidak dilakukan pemasangan drain kemudian dilakukan follow up untuk menilai lamanya perawatan pascaoperasi pada apendisitis perforasi. Lokasi penelitian telah 
dilakukan di RSUD dr. Moewardi Surakarta dan di beberapa rumah sakit satelit yang ditunjuk. Waktu penelitian dilakukan pada bulan Januari 2017. Populasi dalam penelitian ini adalah pasien apendisitis perforasi yang dilakukan apendiktomi. Teknik pengambilan sampel dengan random sampling, besar sampling yang digunakan dihitung berdasarkan rumus slovin dengan 20 sampling Jenis penelitian eksperimen semu. Analisis data uji statistik yang digunakan uji mann whitney, untuk membedakan atau komparasi 2 kelompok sampel. Teknik ini digunakan untuk membandingkan dua variabel terukur berskala kategorikan (nominal atau ordinal) (Dahlan, 2013).

\section{HASIL DAN PEMBAHASAN}

Tabel 1 Karakteristik responden berdasarkan umur

\begin{tabular}{ccc}
\hline Umur & Frekuensi & $\%$ \\
\hline$<20$ Tahun & 3 & 15 \\
21-39 Tahun & 8 & 40 \\
40-60 Tahun & 9 & 45 \\
\hline Total & 20 & 100
\end{tabular}

Sumber: Data Primer 2017

Karakteristik responden berdasarkan umur mayoritas responden berumur antara 40-60 tahun $(45 \%)$.

Tabel 2 Karakteristik responden berdasarkan jenis kelamin

\begin{tabular}{ccc}
\hline Umur & Frekuensi & $\%$ \\
\hline Laki-laki & 11 & 55 \\
Perempuan & 9 & 45 \\
\hline Total & 20 & 100 \\
Sumber: Data Primer 2017 &
\end{tabular}

Jenis kelamin pasien apendisitis perforasi mayoritas berjenis kelamin laki-laki (55\%).

Tabel 3 Gambaran deskriptif komplikasi luka operasi

\begin{tabular}{ccccc}
\multicolumn{3}{c}{ apendisitis } \\
\hline \multirow{2}{*}{ Komplikasi } & \multicolumn{2}{l}{ Tanpa Drain } & \multicolumn{2}{c}{ Drain } \\
\cline { 2 - 5 } & $\mathrm{F}$ & $\%$ & $\mathrm{~F}$ & $\%$ \\
\hline Tanpa Komplikasi & 10 & 100 & 10 & 100 \\
Dengan Komplikasi & 0 & 0 & 0 & 0 \\
\hline Total & 10 & 100 & 10 & 100
\end{tabular}

Dari tabel 3 diketahui bahwa pasien pascaoperasi apendisitis perforasi baik yang dipasang drain maupun yang tidak dipasang drain semuanya tidak mengalami komplikasi pada luka $(100 \%)$.

Tabel 4 Gambaran deskriptif penyembuhan luka pascaoperasi apendisitis perforasi

\begin{tabular}{ccccc}
\hline \multirow{2}{*}{ Penyembuhan Luka } & \multicolumn{2}{c}{ Tanpa Drain } & \multicolumn{2}{c}{ Drain } \\
\cline { 2 - 5 } & $\mathrm{F}$ & $\%$ & $\mathrm{~F}$ & $\%$ \\
\hline Baik & 10 & 100 & 10 & 100 \\
Tidak Baik & 0 & 0 & 0 & 0 \\
\hline Total & 10 & 100 & 10 & 100 \\
& \multicolumn{2}{c}{ Sumber: Data Primer 2017} & &
\end{tabular}

Penyembuhan luka pascaoperasi apendisitis perforasi baik yang dipasang drain maupun yang tidak dipasang drain semuanya mengalami proses penyembuhan luka dengan baik (100\%).

Tabel 5 Gambaran statistik deskriptif lama rawat inap pasien apendicitis

\begin{tabular}{ccccc}
\hline Kategori & Minimum & Maximum & Mean & $\begin{array}{l}\text { Standar } \\
\text { Deviasi }\end{array}$ \\
\hline $\begin{array}{c}\text { Tanpa } \\
\text { Dipasang } \\
\text { Drain }\end{array}$ & 4 & 6 & 5 & 0,667 \\
$\begin{array}{c}\text { Dipasang } \\
\text { Drain }\end{array}$ & 5 & 8 & 6,7 & 0,949 \\
\hline
\end{tabular}

Sumber: Data Primer, 2017

Berdasarkan tabel 4.4, lama rawat inap pasien operasi apendisitis perforasi tanpa dipasang drain lama rawat inap terendah adalah 4 hari dan paling lama 6 hari, sedangkan yang dipasang drain cenderung lebih lama, yaitu tercepat 5 hari dan terlama 8 hari. Jika dilihat dari nilai meannya juga terlihat bahwa pasien yang dipasang drain lebih lama dibandingkan dengan pasien yang tidak dipasang drain.

Tabel 7 Hasil uji beda Mann Whitney

\begin{tabular}{|c|c|c|c|c|c|}
\hline & $\begin{array}{l}\text { Rank } \\
\text { Mean }\end{array}$ & $\mathrm{U}$ & W & $\mathrm{Z}$ & $\mathrm{P}$ \\
\hline Tanpa & & & & & \\
\hline $\begin{array}{c}\text { Dipasang } \\
\text { Drain }\end{array}$ & 6,30 & & & & \\
\hline $\begin{array}{c}\text { Dipasang } \\
\text { Drain }\end{array}$ & 14,70 & & & & \\
\hline $\begin{array}{c}\text { Hasil Uji } \\
\text { Beda }\end{array}$ & & 8,000 & 63,000 & $-3,285$ & 0,001 \\
\hline
\end{tabular}

Sumber: Data Primer, 2017 
Jika dilihat dari nilai rank mean-nya pada kelompok tanpa dipasang drain rerata peringkatnya 6,30 lebih rendah daripada rerata peringkat kelompok yang dipasang drain, yaitu 14,70, selisih 8,4. Hasil uji analisis dengan nilai $\mathrm{p}=$ 0,001, sehingga dapat ditarik kesimpulan bahwa Ho ditolak, ada perbedaan lama perawatan yang signifikan antara pasien pascaoperasi apendisitis perforasi dengan yang dipasang drain dan yang tidak dipasang drain.

Apendisitis perforasi berhubungan dengan tingkat mortalitas yang tinggi. Peradangan akut pada apendiks memerlukan tindakan pembedahan segera untuk mencegah terjadinya komplikasi berbahaya (Schwartz et al. 2014). Apendisitis yang tidak tertangani segera akan meningkatkan risiko terjadinya perforasi dan pembentukan masa peri apendikular (Tzanakis, 2005; Vasser, 2012; Riwanto et al., 2010; Brunner \& Suddarth, 2014). Abses intra-abdominal merupakan komplikasi yang paling umum setelah apendisitis perforasi. Drain intraabdomen banyak digunakan oleh ahli bedah di praktik klinis saat ini (Curran dan Muenchow 1993; Lund dan Murphy 1994; Fishman et al. 2000). Namun demikian, drain intraabdomen setelah operasi apendisitis dalam kasus apendisitis perforasi masih kontroversi (Akoyun, 2012).

Karakteristik pasien pascaoperasi apendisitis perforasi berdasarkan umur dari 20 responden mayoritas responden berumur antara 40-60 tahun (45\%). Hasil penelitian ini sesuai dengan hasil penelitian yang dilakukan oleh Ghnnam (2012) juga membuktikan tingkat perforasi pada usia tua jauh lebih tinggi dibanding kelompok usia lain dengan persentase 69,5\% dibanding kelompok lain hanya $20 \%$. Salah satu penyebab tingginya tingkat perforasi pada usia tua adalah tidak khasnya gejala yang muncul ketika diperiksa. Penelitian sebelumnya mendapatkan 25 dari 95 pasien usia tua tidak menunjukkan nyeri pada perut yang merupakan gejala klasik apendisitis (Ghnnam, 2012). Teori Mansjoer (2010), pada orang tua perforasi mudah terjadi karena telah ada gangguan pembuluh darah. Sedangkan pada anak-anak, kerena momentum lebih pendek dan apendiks lebih panjang, maka dinding apendiks lebih tipis. Jenis kelamin pasien apendisitis perforasi hampir sama antara penderita laki-laki (55\%) dan perempuan (45\%). Insiden apendisitis pada laki-laki dan perempuan umumnya sebanding, kecuali pada umur 2030 tahun sedikit lebih banyak pada laki-laki dibandingkan pada perempuan dengan rasio 1,4 : 1. Insiden tertinggi terjadi pada umur ini (Riwanto et al., 2010).

Hasil penelitian ini menunjukkan bahwa lama rawat inap pasien pasca operasi apendisitis perforasi tanpa dipasang drain lama rawat inap terendah adalah 4 hari dan paling lama 6 hari, sedangkan yang dipasang drain cenderung lebih lama, yaitu tercepat 5 hari dan terlama 8 hari. Jika dilihat dari nilai meannya juga terlihat bahwa pasien yang dipasang drain lebih lama dibandingkan dengan pasien yang tidak dipasang drain. Hasil penelitian ini sesuai dengan hasil penelitian yang dilakukan oleh Song (2015), bahwa pemasangan drain dapat memperlama pasien dirawat di rumah sakit dan meningkatkan risiko mengalami abses dan infeksi. Dampak lain dari abses juga memengaruhi lama pasien dirawat di rumah sakit dan meningkatkan biaya di rumah sakit, oleh karena itu, pencegahan abses intra-abdominal setelah apendektomi sangat penting (Gasior et al. 2013). Jika dilihat dari proses penyembuhan luka operasi apendisitis perforasi dan terjadinya komplikasi baik yang dipasang drain maupun yang tidak dipasang drain semuanya mengalami proses penyembuhan luka dengan baik (100\%) dan 100\% tidak mengalami komplikasi. Sehingga hasil ini tidak sesuai dengan hasil penelitian oleh Memon, et al, 2002 dengan hasil bahwa tindakan pascaoperasi apendisitis perforasi yang dipasang drain mempunyai risiko lebih rendah terjadinya komplikasi dibandingkan dengan yang tidak dipasang drain, sehingga proses penyembuhan luka pasien yang dipasang drain lebih cepat dibandingkan dengan yang tidak dipasang. Hasil penelitian Rather (2013), bahwa tidak ada beda antara tindakan pemasangan drainase dan tanpa drainase terhadap komplikasi dan penyembuhan luka.

Hasil penelitian ini menunjukkan bahwa ada perbedaan penggunaan drain dan tanpa penggunaan drain intra abdomen pada pasien apendisitis terhadap lama perawatan pascaoperasi laparotomi apendisitis perforasi dengan nilai sig $<0,001(\mathrm{p}=0,000)$. Hasil penelitian Song (2015) menunjukkan hasil yang sama dengan nilai $\mathrm{p}<$ 0,001 , ada perbedaan lama rawat inap antara yang dipasang drain dengan yang tidak dipasang drain pada penderita apendisitis perforasi. Pemasangan 
drain adalah salah satu cara untuk menghindari terjadinya peningkatan tekanan intra-abdomen. Ini sesuai dengan laporan dari Offner (2001) dkk dengan menghindari primary facial clossure pada initial laparotomy dapat meminimalisasi risiko terjadinya ACS (Abdominal Compartment Syndrome). Dengan dipasangnya drainase kadang memberikan masalah baru seperti timbulnya komplikasi sehingga menghambat penyembuhan luka. Penumpukan sekresi dapat membantu proses penyembuhan luka. Terjadinya komplikasi akan mempengaruhi proses penyembuhan luka sehingga akan berpengaruh juga dengan lama rawat inap di rumah sakit (Offner, 2001).

\section{SIMPULAN}

Ada perbedaan yang signifikan antara lama perawatan pasien pascaoperasi apendisitis perforasi dengan yang dipasang drain dengan yang tidak dipasang drain dengan nilai $p=0,001$ dengan hasil penelitian perawatan pascalaparotomi apendisitis perforasi yang tidak mengunakan drain waktunya lebih pendek dari pada menggunakan drain intra abdomen.

\section{DAFTAR PUSTAKA}

Akoyun I, Tuna AT. 2012. Advantages of Abandoningabdominal Cavity Irrigation and Drainage in Operations Performed Onchildrenwith Perforated Appendicitis. Journal Pediatric Surg.; 47:1886-90.

Brunner\& Suddarth. 2014. Keperawatan Medikal Bedah. Edisi 1. Jakarta: EGC.

Burkitt H.G, Clive R.G.Q, and Joanna B.R. 2007. Appendicitis. In: Essential Surgery Problem, Diagnosis and Manajement. $4^{\text {th }}$ ed. China: Elsevier: pp. 389-94.

Curran TJ, Muenchow SK. 1993. The Treatment of Complicated Appendicitisin Children Using Peritoneal Drainage: Results From a Public Hospital. JPediatr Surg 28(2):204-208.

Dahlan M.S. (2013). Statistik untuk Kedokteran dan Kesehatan. Jakarta: Salemba Medika.

Dandapat MC, Panda C. 1992. A Perforated Appendix: Should We Drain?. J Indian Med Assoc;90: 147148 [PMID: 1522303].

Depkes RI. 2011. Survei Kesehatan Rumah Tangga (SKRT). Jakarta: Departemen Kesehatan Republik Indonesia.

Fishman SJ, Pelosi L, Klavon SL, O’Rourke EJ. 2000. Perforated Appendicitis:Prospective Outcome Analysis for 150 Children. J Pediatr Surg35(6): 923-926.

Gasior AC, Marty Knott E, Ostlie DJ, St Peter SD. 2013. To Drain or Not to Drain: Analysis of Abscess Drains in the Treatment of Appendicitis with Abscess. PediatrSurg Int;29:455-8.

Ghnnam WM .2012. Elderly Versus Young Patients with Appendicitis 3 Years Experience. Alexandria Journal of Medicine. 48: 1, pp: 9-12.

Jeo WS, Lalisang TJM. 2003. Intra abdominal pressure after major laparotomy. J1 Bedah Indonesia 31 (4): 169-74.

Lee JH, Park YS, Choi JS. 2010. The Epidemiology of Appendicitis and Appendectomy in South Korea: National Registry Data. Journal Epidemiology. 20:2, pp:97-105.

Lund DP, Murphy EU. 1994. Management of Perforated Appendicitis in Children: a Decade of Aggressive Treatment. J Pediatr Surg 29(8):1130-1133.

Mansjoer A, dkk. 2010. Kapita Selekta Kedokteran. Edisi ke-4. FKUI. Jakarta: Medica Aesculpalus.

Memon MA, Memon B, Memon MI, Donohue JH. 2002. The Uses and Abuses of Drainsin Abdominal Surgery. Hosp Med; 63:282-8.

Offner PJ, de Souza AL, Moore EE, biffl WL. 2001. Avoidance of Abdominal Compartment Syndrome in Damage-Control Laparotomy After Trauma. 136 (6): 676-681.

Rather SA, Bari, SUL, Malik, AA, dan Khan A, 2013. Drainage Vs No Drainage in Secondary Peritonitis With Sepsis Following Complicated Appendicitis In Adults In The Modern Era Of Antibiotics. 
World J Gastrointest Surg; 5(11): 300-305ISSN 1948-9366 (online). Online Submissions: http://www.wjgnet.com/esps/bpgoffice@wjgnet.com: doi:10.4240/wjgs.v5.i11.300.

Riwanto, Ign. et al., 2010. Usus Halus, Apendiks, Kolon, dan Anorektum. In: Sjamsudihajat, R. et al., ed. Buku Ajar Ilmu Bedah. Edisi 3. Jakarta:EGC, 755-762.

Schwartz MZ, Tapper D, Solenberger RI. 2014. Management of Perforated Appendicitis in Children. The Controversy Continues. Ann Surg197(4):407-411.

Shrestha R, Ranabhat SR, Tiwari M. 2012. Histopathologic Analysis of Appendectomy Specimens. Journal of Pathology of Nepal. 2, pp: 215-219.

Song RY, Jung K. 2015. Drain Insertion After Appendectomy in Children with Perforated Appendicitis Based on a Single-Center Experience. Annals of Surgical Treatment and Research. ISSN 2288-6796: http://dx.doi.org/10.4174/astr.2015.88.6.341.

St Peter SD, Adibe OO, Iqbal CW, Fike FB, Sharp SW, Juang D, et al. 2012. IrrigationVersus Suction Alone During Laparoscopic Appendectomy for Perforated Appendicitis: A Prospective Randomized Trial. Ann Surg;256:581-5.

Tzanakis NE, Efstathiou SP, Danulidis K, Rallis GE, Tshioulus DI,Chatzivasiliou A et al. 2005. A New Approach to Accurate Diagnosis of Acute Appendicitis. World J. Surg.; 29,1151-1156.

Vasser HM, Anaya DA. 2012. Acute appendicitis. In Jong EC, Stevens DL eds. Netter's Infectious Disease. Philadelphia: Saunders Elsevier.

Yamini D, Vargas H, Bongard F, Klein S, Stamos MJ. 1998. Perforated Appendicitis: is it Truly a Surgical Urgency?. Am Surg: 64 (10): 970-975. 